\title{
In vitro and in vivo targeted delivery of IL-10 interfering RNA by JC virus-like particles
}

\author{
Meng-Ing Chou ${ }^{\dagger 1}$, Yu-Fan Hsieh², Meilin Wang ${ }^{3}$, Jinghua Tsai Chang ${ }^{4}$, Deching Chang ${ }^{5}$, Moncef Zouali6,7 and \\ Gregory J Tsay*1,2,8
}

\begin{abstract}
Background: RNA interference (RNAi) is a powerful tool to silence gene expression post-transcriptionally. Delivering sequences of RNAi in vivo remains a problem. The aim of this study was to use JC virus (JCV) virus-like particles (VLPs) as a vector for delivering RNAi in silencing the cytokine gene of IL-10.
\end{abstract}

Methods: JCV VLPs were generated by recombinant JCV VP1 protein in yeast expression system. DNA fragment containing IL-10 shRNA was packaged into VLPs by osmotic shock.

Results: In RAW 264.7 cells, IL-10 shRNA was found to reduce IL-10 expression by 85 to 89\%, as compared with VLPs alone. IL-10 shRNA did not cross-react with TNF-alpha mRNA or influence the expression of TNF-alpha. In BALB/c mice IL-10 shRNA could reduce 95\% of IL-10 secretion. Surprisingly, it also down regulated TNF-alpha expression.

Conclusions: We show for the first time that JCV VLPs empty capsids are competent vectors to deliver RNAi and are nontoxic to cells, suggesting that JCV VLPs is an efficient agent to deliver RNAi in both murine macrophage cells and $\mathrm{BALB} / \mathrm{c}$ mice. This system provides an efficient means for delivering the RNAi for gene therapy purposes.

\section{Background}

Transfection of RNA interference (RNAi) into living cells is a major technique in studying the biological function of genes and for their potential treatment of human diseases. There are considerable excitements about its potential therapeutic applications in human diseases [13]. RNAi offers the prospects of higher specificity, lower immunogenicity, and greater disease modification than current antibody therapies for systemic autoimmune diseases (AID) such as systemic lupus erythematosus (SLE). The major challenge in turning RNAi into an effective therapeutic strategy is the delivery system.

$\mathrm{JC}$ virus (JCV), a human polyomavirus, belongs to the polyomaviridae. The JC virion contains three capsid proteins (VP1, VP2 and VP3) and a viral mini chromosome. VP1 is the major capsid protein constituting approximately $75 \%$ of the total proteins. Chang et al. [4] found that JCV VP1 could be transported into the nucleus and self-assembled to form capsid-like particles (VLPs) similar to the natural empty capsid without the involvement

\footnotetext{
* Correspondence: gjt@csmu.edu.tw

${ }^{1}$ Institute of Medicine, Chung Shan Medical University, Taichung, Taiwan

+ Contributed equally

Full list of author information is available at the end of the article
}

of the viral minor capsid proteins, VP2 and VP3. JCV VLPs can be generated by recombinant JCV VP1 protein in yeast expression. The recombinant VLPs were demonstrated to be able to package and deliver exogenous DNA into mammalian cell $[5,6]$.

Patients with SLE produce large amounts of IL-10 in their serum which correlate with disease activity $[7,8]$. Administration of IL-10 antagonists has been found to be beneficial in the management of human SLE [9] or its murine $[10,11]$. The decrease in IL-10 level may contribute to the amelioration of the disease symptoms. Thus, IL-10 appears to play a key role in the autoimmune responses and might serve as a therapeutic target for SLE.

In this study, we show that JCV VLPs can be used as a gene delivery vector for IL-10 RNAi and for the possibility of gene therapy in SLE in the future.

\section{Methods \\ Cell culture}

The murine macrophage RAW 264.7 cell line was grown in $90 \%$ DMEM and $10 \%$ fetal bovine serum (FBS) obtained from Gibco BRL (Grand Island, NY) at a temperature of $37^{\circ} \mathrm{C}$ under a humidified and $5 \% \mathrm{CO}_{2}$ atmosphere. 


\section{Cell viability}

Cells were counted using the trypan blue exclusion assay. The extent of cell viability was calculated and the viable cell numbers from experiment groups were compared with those in the untreated control groups.

\section{JC virus (JCV) virus-like particles (JCV VLPs)}

JCV VLPs were generated by recombinant JCV VP1 protein in yeast expression system [12]. VLPs were further purified by sucrose gradient (10-30\%) centrifugation for $40 \mathrm{~min}$ at 35,000 rpm. Particle-containing fractions were analyzed by hemagglutination activity after dialyzis in Tris buffer. VLPs were concentrated by ultracentrifugation for $3 \mathrm{~h}$ at 35,000 rpm and resuspended in $100 \mu \mathrm{l}$ PBS.

\section{Construction of shRNA templates of IL-10}

Two target sites were selected from mouse IL-10 (NM_000572) cDNA for generating two short hairpin RNA (shRNA) templates. Sequences for the target sites are GCTTCCAAACTGGATATAA and GTCTTCTGGAGTTCCGTTT respectively. For each shRNA template, two oligonucleotides containing partial complementary sequence of the shRNA with an overlapping loop region were synthesized and annealed as a shRNA cassette. The shRNA cassette was inserted into pcDNA/HU6 vector and introduced into $E$. coli[13]. The HU6-shRNA DNA fragment was polymerase chain reactions (PCR) amplified by a set of primers on the vector of flanking the HU6-shRNA template. Oligonucleotides used for target site \#1 (target site sequences are in bold). IL10-RNAi-1-Forward: 5'-GATCCGCTTCCAAACTGGATATAATTCAAGAGAT; IL10-RNAi-1-Reverse: 5'AGCTTAAAAAAGCTTCCAAACTGGATATAATCTC TTGAAT'; Oligonucleotides used for target site \#2 (target site sequences are in bold); IL-10 RNAi-2-Forward: 5'GATCCGTCTTCTGGAGTTCCGTTTTTCAAGAGA A; IL10-RNAi-2-Reverse: 5'-AGCTTAAAAAAGTCTTC TGGAGTTCCGTTTTCTCTTGAAA.

\section{Packaging shRNA into JCV VLPs}

Briefly, $100 \mu \mathrm{g}$ of purified JCV-VLPs were mixed with 1 $\mu \mathrm{g}$ of PCR amplified shRNA template in capsid buffer (150 mM NaCl, $10 \mathrm{mM}$ Tris- $\mathrm{HCl}, 0.01 \mathrm{mM} \mathrm{CaCl}_{2}$ ) and was incubated for $10 \mathrm{~min}$ at $37^{\circ} \mathrm{C}$. Osmotic shock was achieved by diluting the mixture with $350 \mu \mathrm{l}$ of distilled water and incubated for $20 \mathrm{~min}$ at $37^{\circ} \mathrm{C}$ [14].

\section{VLPs with IL-10 shRNA template or pEGFP-N3 for RAW264.7 cells}

RAW 264.7 cells were grown on cover slips in $35-\mathrm{mm}$ dishes overnight with DMEM supplement with $10 \%$ fetal calf serum. Cells were washed with PBS and incubated with $10 \mu \mathrm{g}$ of VLPs containing the shRNA or pEGFP-N3 for $1 \mathrm{~h}$ at $37^{\circ} \mathrm{C}$. Cells were then washed with PBS three times. Complete DMEM was added to the culture and

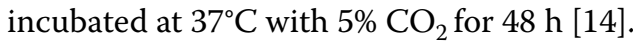

\section{Real-time PCR}

All studies were carried out in a designated PCR clean area. RNA was extracted from cells using a Trizol reagent (Invitrogen, Carlsbad, CA, USA) according to the manufacturer's instructions. Total RNA was isolated from the RAW 264.7 cells incubated with LPS or VLPs with IL-10 shRNA. RNA samples were resuspended in diethyl pyrocarbonate (DEPC)-treated water, quantified, and then stored at $-80^{\circ} \mathrm{C}$ until used. RNA concentration and purity were determined by a spectrophotometer by calculating the ratio of optical density at wavelengths of 260 and 280 $\mathrm{nm}$. The first-strand of cDNA for RT-PCR was synthesized from the total RNA ( $2 \mu \mathrm{g})$ using the Promega RTPCR system (Promega, Madison, Wisconsin, USA). The cDNA was denatured for $10 \mathrm{~min}$ at $95^{\circ} \mathrm{C}$. Specific DNA fragments were amplified with a Max3000p Stratagene cycler with 40 cycles of $15 \mathrm{~s}$ at $95^{\circ} \mathrm{C}, 60 \mathrm{~s}$ at $60^{\circ} \mathrm{C}$ and $30 \mathrm{~s}$ at $72^{\circ} \mathrm{C}$. The oligonucleotide primers were as follows: for mouse IL-10, 5'-CACTACCAAAGCCACAAAGCA-3' (forward) and 5'-AGGAGTCGGTTAGCAGTATGTT-3' (reverse). The amount of amplified DNA fragments encoding IL-10 was normalized to that of fragments encoding $18 \mathrm{~s}$ rRNA. Results are presented as the 'relative expression' in gene expression.

\section{Animals}

Six-week-old female BALB/c mice were obtained from the National Animal Center, Taipei, Taiwan. The mice were divided into four groups with the treatment of PBS, LPS, LPS-VLPs-irrelevant shRNA and LPS-VLPs-IL-10 shRNA. LPS was from E. coli (Sigma Chemical Co. st. Louis, MO, USA; serotype 0111: B4). The animal experiments were approved by the Animal Research Committee of Chung Shan Medical University, Taiwan.

\section{IL-10 shRNA in BALB/c mice}

Groups of $\mathrm{BLAB} / \mathrm{c}$ mice were intraperitoneally injected with a single dose of $25 \mu \mathrm{g}$ of LPS in $100 \mu \mathrm{l}$ PBS. After two hours, mice were introvenousely treated with $250 \mu \mathrm{g}$ of JCV VLPs with IL-10 shRNA, or irrelevant shRNA, respectively. After 6, 12 and 24 h of treatments, serum samples were collected and tested for IL-10 and TNF- $\alpha$ levels by real-time PCR and cytokine enzyme-linked immunosorbent assay (ELISA).

\section{Cytokine enzyme-linked immunosorbent assay (ELISA)}

Conditioned RAW 264.7 cells medium and mouse serum were collected for subsequent analysis of cytokines, respectively. The levels of IL-10 and TNF- $\alpha$ were analyzed by using cytokines specific ELISA kits (IBL Co. Ltd, Gunma, Japan). 


\section{Statistical analysis}

Statistical analysis was performed using the paired $t$-test. A statistically significant difference was considered to be present at $P<0.05$.

\section{Results}

Purification of JCV virus-like particles (VLPs)

Recombinant JCV VLPs protein in yeast cells was purified and identified by SDS-PAGE (Fig. 1A) and Western blot (Fig. 1B) using the rabbit antibody to JCV VLPs. The JCV VLPs showed strong hemagglutination activity and the activity was completely inhibited by JCV-positive human serum. As the control, RAW 264.7 cells were pseudoinfected with VLPs (Fig. 1C (I)), VLPs packaged with pEGFP-N3 were analyzed by light microscopy (Fig. $1 \mathrm{C}$ (II)) and fluorescence microscopy (Fig. 1C (III)). All RAW 264.7 cells transfected with VLPs expressed green fluorescence (Fig. 1C (III)).

\section{Suppression of IL-10 expression by IL-10 shRNA in RAW 264.7 cells}

Two preparations of IL-10 shRNA (IL-10i-1 and IL-10i-2) were packaged into JCV VLPs by osmotic shock and were confirmed by PCR (Fig. 2A). The morphology of RAW

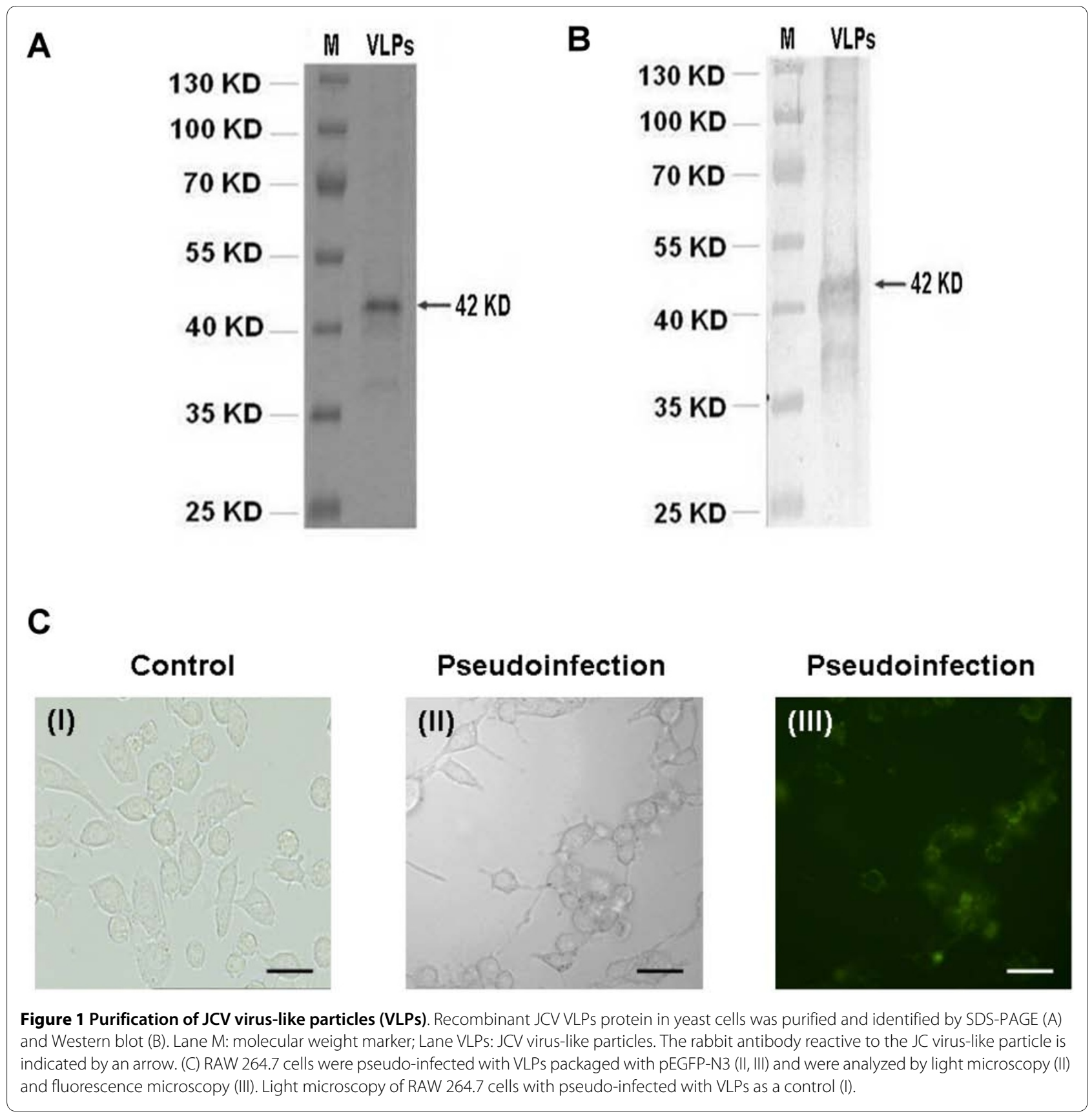


264.7 cells with pseudoinfection of VLPs-IL-10 shRNA was shown in Fig. 2B. The cells with the pseudoinfection of VLPs were stained with DAPI (Fig. 2B) and the cell viability was detected by trypan blue staining (Fig. 2C). Figure 3 shows suppression of IL-10 expression in RAW 264.7 cells. Both IL-10i- 1 and IL-10i-2 could reduce IL-10 expression about $85 \%$ and $89 \%$, respectively, by real-time PCR compared to VLPs only (Fig. 3A) $(p<0.005)$. The expression of TNF- $\alpha$ was not affected by IL-10 shRNA treatment (Fig. 3B). The suppression of IL-10 by IL-10 shRNA was dose-dependent (Fig. 3C). Figure 3(D) shows the suppression of IL-10 by IL-10 shRNA after LPS stimulation in RAW 264.7 by real-time PCR. The irrelevant shRNA did not suppress the production of IL-10. The IL-
10 shRNA packaged in JCV VLPs could sufficiently suppress IL-10 expression in RAW 264.7 cells. We also found that the expression of TNF- $\alpha$ was not affected by IL-10 shRNA after LPS treatment in RAW264.7 cells by ELISA (Fig. 3E). Figure 3F shows reduction of IL-10 by IL-10 shRNA after LPS treatment in RAW 264.7 cells at 36 and 48 hours by ELISA. In addition, the IL-10 suppressive effects could be sustained for $48 \mathrm{~h}$ by IL- 10 shRNA. Thus, we found suppression of IL-10 by VLPs-IL-10 shRNA not only at mRNA levels but also at protein level.

\section{Effects of IL-10 shRNA on cytokines production of IL-10 and TNF-a in BALB/c mice}

After LPS treatment in mice, IL-10 was increased and the peak concentration of IL-10 was at $6 \mathrm{~h}$ then decreased at

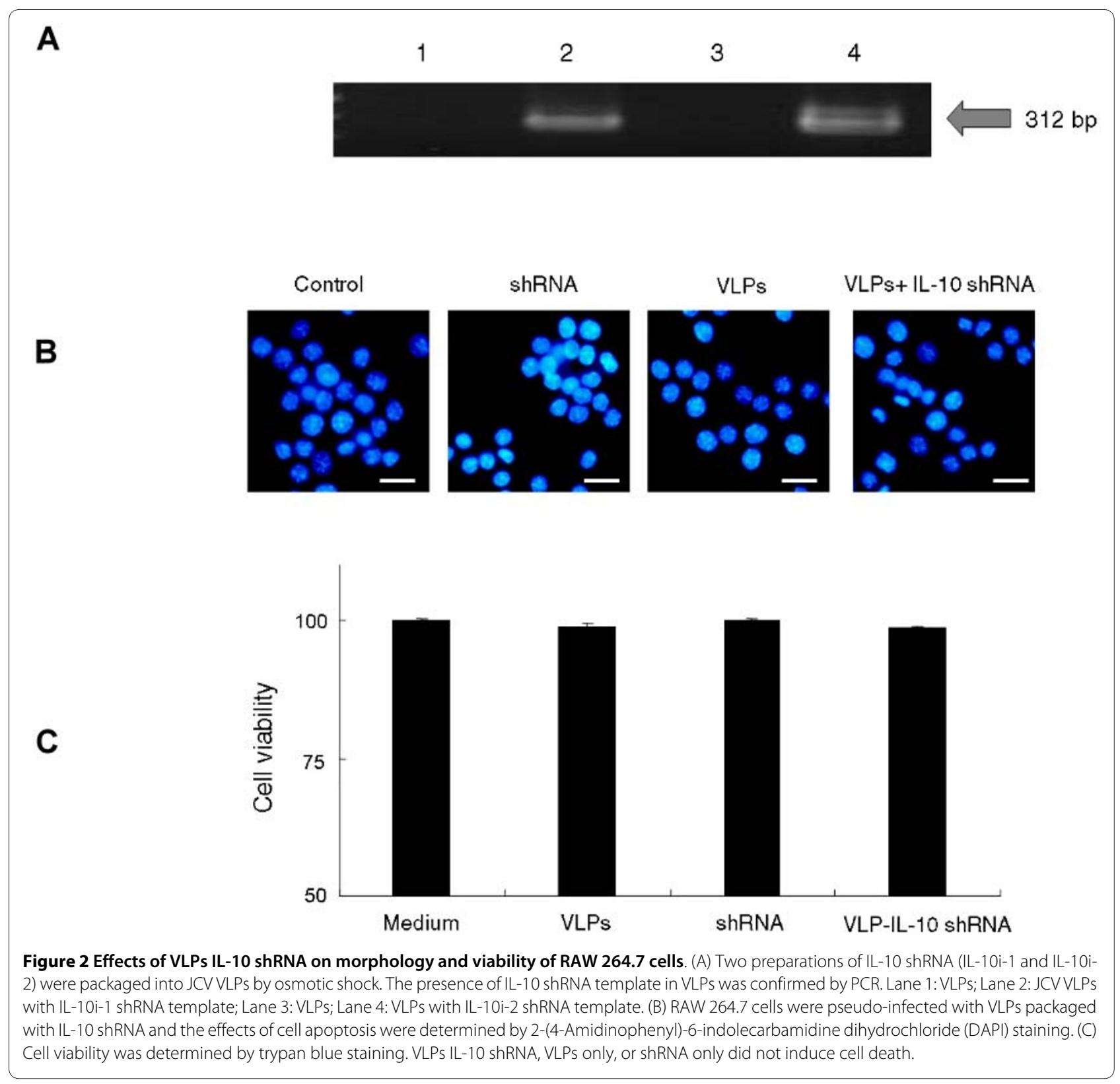




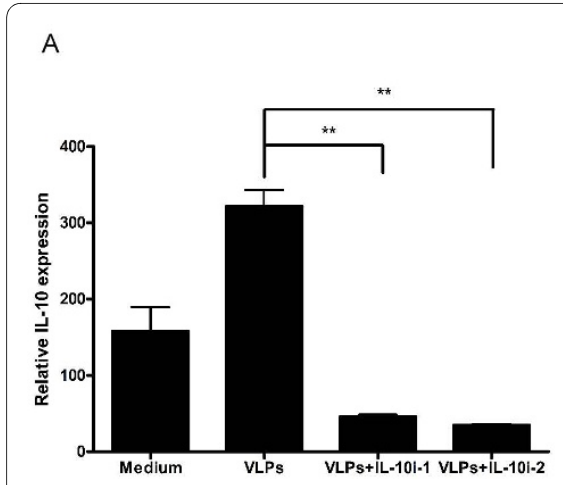

B

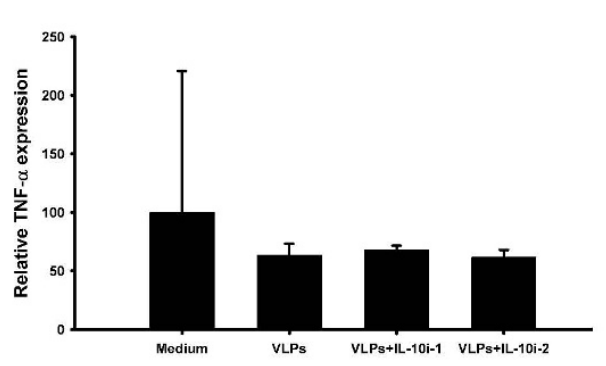

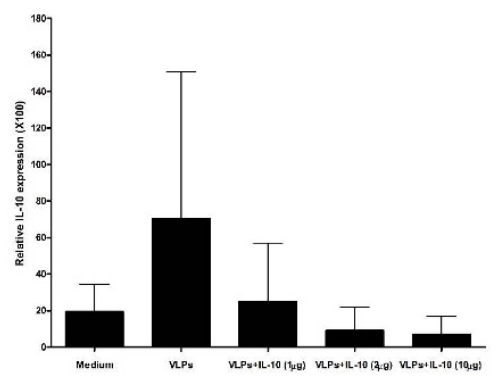

$E$

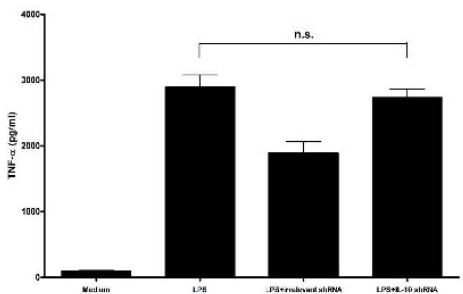

$\mathrm{F}$

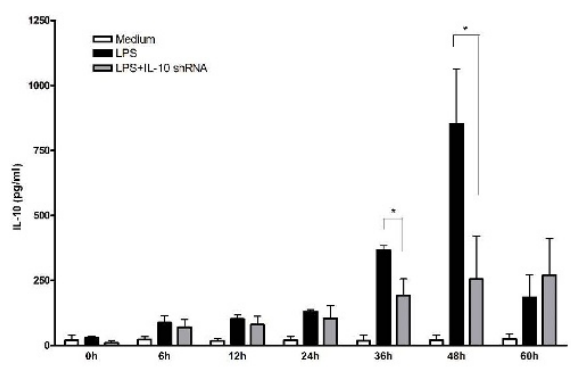

Figure 3 Suppression of IL-10 expression in RAW 264.7 cells by two IL-10 shRNA preparations. Cells were cultured with either IL-10 shRNA (IL10i-1 or IL-10i-2) or irrelevant shRNA for $24 \mathrm{~h}$. After washing, gene expression was analyzed by real-time PCR. Represented are the mRNA levels of target gene relative to those of $18 \mathrm{~s}$ rRNA. (A) Suppression of IL-10 expression was analyzed by real-time PCR. (B) IL-10 shRNA did not cross-react with TNF-a mRNA and influence the expression of TNF-a in RAW 264.7 cells. Relative TNF-a expression was analyzed by Real-time PCR. (C) Suppression of IL-10 expression by various doses of IL-10 shRNA in RAW 264.7 cells. (D) RAW 264.7 cells $\left(2 \times 10^{5}\right)$ were pre-treated with LPS $(2 \mu \mathrm{g} / \mathrm{ml})$ for $90 \mathrm{~min}$. Cells were then cultured with either IL-10 shRNA (IL-10i-2) or irrelevant shRNA for $24 \mathrm{~h}$. After washing, IL-10 expression was analyzed by real-time PCR. Represented are the mRNA levels of IL-10 relative to those of $18 \mathrm{~s}$ rRNA. *: $P<0.05$; ***: $P<0.005$. (E) RAW 264.7 cells $\left(2 \times 10^{5}\right)$ were pre-treated with LPS $(2 \mu \mathrm{g} /$ $\mathrm{ml}$ ) for $90 \mathrm{~min}$. Cells were then cultured with either IL-10 shRNA (IL-10i-2) or irrelevant shRNA for $36 \mathrm{~h}$. After $36 \mathrm{~h}$, conditioned medium was collected for analysis of TNF-a expression by ELISA. (F) RAW 264.7 cells $\left(2 \times 10^{5}\right)$ were pre-treated with LPS $(2 \mu \mathrm{g} / \mathrm{ml})$ for 90 min. Cells were then cultured with either IL-10 shRNA (IL-10i-2) or irrelevant shRNA for 0, 6, 12, 24, 36, 48 and 60 hours. After 0, 6, 12, 24, 36, 48 and 60 hours, conditioned medium was collected for analysis of IL-10 expression by ELISA. *: $P<0.05$.

12 and $24 \mathrm{~h}$. In the group of mice with LPS-irrelevant shRNA treatment, IL-10 was also increased at $6 \mathrm{~h}$, but the peak concentration was delayed to $12 \mathrm{~h}$. The concentration of IL-10 was higher in the group of mice treated with LPS-irrelevant shRNA than these with LPS only treatment (Fig. 4). The irrelevant shRNA itself could obviously induce IL-10 production. The production of IL-10 was decreased after VLPs with IL-10 shRNA treatment (93\% of suppression) $(P<0.05)$. There was no suppression of IL-10 in the control groups treated with PBS, LPS and LPS-VLP-irrelevant shRNA.

\section{Effects of TNF- $a$}

TNF- $\alpha$ was also increased after LPS injection and the peak concentration of TNF- $\alpha$ was at $24 \mathrm{~h}$. TNF- $\alpha$ was increased in the groups with LPS and LPS-irrelevant shRNA treatment. The concentration of TNF- $\alpha$ was decreased after JCV VLPs IL-10 shRNA treatment (81\% of suppression) (Fig. 4). IL-10 shRNA did not cross-react with TNF- $\alpha$ mRNA and influence the expression of TNF$\alpha$ in RAW 264.7 cells (Fig. 3B). In BALB/c mice, however, down regulation of IL-10 by IL10 shRNA could affect TNF- $\alpha$ expression (Fig. 4).

\section{Effects on survival}

All mice treated with PBS only or LPS-VLPs-IL-10 shRNA survived in the end of the experiment, but all mice treated with LPS only or LPS-VLPs irrelevant shRNA died after $24 \mathrm{~h}$ of treatment. The mice treated with LPS-VLPs-IL-10 shRNA had longer lifespan than those treated with LPS-VLPs irrelevant shRNA or LPS. (Fig. 5)

\section{Discussion}

We have shown for the first time that JCV VLPs could be used as a vector to deliver IL-10 shRNA in both RAW 


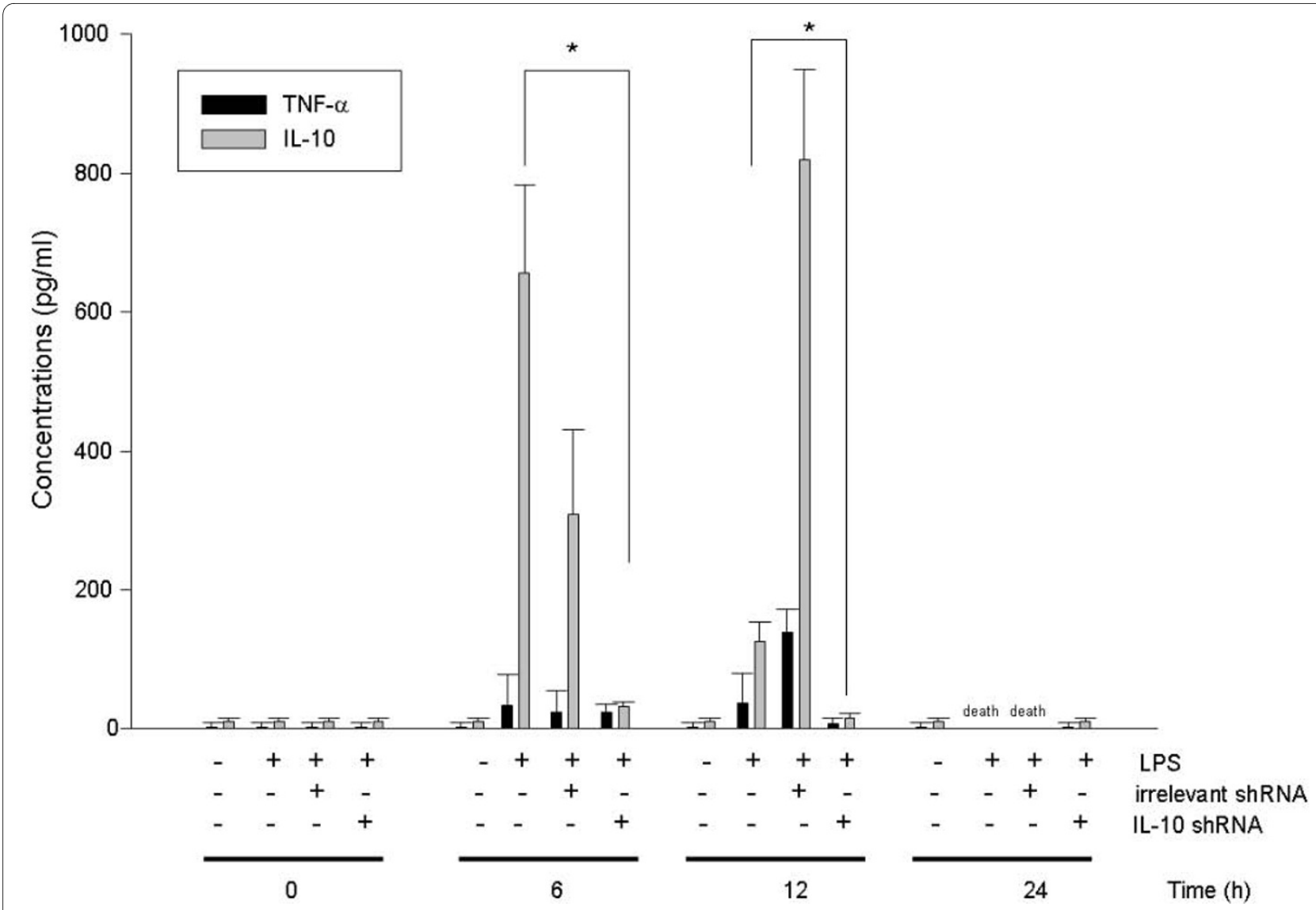

Figure 4 In vivo effects of IL-10 shRNA on production of IL-10 and TNF- $\boldsymbol{a}$ in BALB/c mice. Groups of BALB/c mice were intraperitoneally injected with LPS $(25 \mu \mathrm{g})$. After two hours, mice received VLPs-IL-10 shRNA or irrelevant shRNA intravenously. After 6, 12, 24 and $36 \mathrm{~h}$, serum samples were collected from each mouse and tested for IL-10 and TNF-a levels by ELISA. The level of IL-10 was suppressed after the treatment of IL-10 shRNA. *: $P<$ 0.05 ; $^{* *}: P<0.005$

264.7 cells and BALB/c mice. The JCV VLPs with IL-10 shRNA could effectively silence the IL-10 cytokine both in vitro and in vivo and were not toxic to RAW 264.7 cells. These findings suggest that JCV VLPs is an effective delivery vector for RNAi delivering with potentially therapeutic use for autoimmune diseases such as SLE.

Among methods for gene transfer into cells, viral genedelivery system is a most effective method. In previous studies, we demonstrated that the recombinant IC virus major capsid protein, VP1, is able to self-assemble to form a virus-like particle (VLP) when expressed in the baculovirus [4], E. coli [14] and yeast [12]. In addition, the VLP is able to package exogenous DNA and deliver it into human kidney [14], glioma [5] and colon adenocarcinoma [15] cells. These findings indicate that the JCV VLPs may be used as a gene delivery vector for therapeutic applications. In addition, JCV VLPs may be used for human therapy [15]. In this study, we further extended the findings that JCV VLPs provided an efficient tool for delivering shRNA to silence the targeted RNA. Because of lack of viral nucleic acids in JCV VLPs, JCV do not cause serious risks for infection and are considered as a safe and efficient method for transfection of RNAi. The $\mathrm{JCV}$ receptor is widely distributed among mammalian cells including human, monkey, and mouse. JCV can enter a wide variety of cell types [16]. However, the immune response is a limitation when developing a viral gene delivery vectors. For human polyomaviruses, most adults are seropositive against JCV. It may not beneficial to use the JCV VLPs as a gene delivery vector in such circumstances. Therefore, modification of the JCV VLPs to avoid immune elimination may be useful in advancing the development of the JCV as a gene delivery vector in human.

We used the HU6-shRNA template for expressing RNAi. Since VLPs has a certain DNA packing capacity, to increase the ratio of packed shRNA template, a minimal linear DNA fragment containing HU6 promoter and shRNA template (HU6-shRNA template) was PCR amplified and packed into VLPs. This linear HU6-shRNA template was efficiently packed into VLPs and expressed successfully in cells and animals. Other than more eco- 


\section{Survival curves for mice}

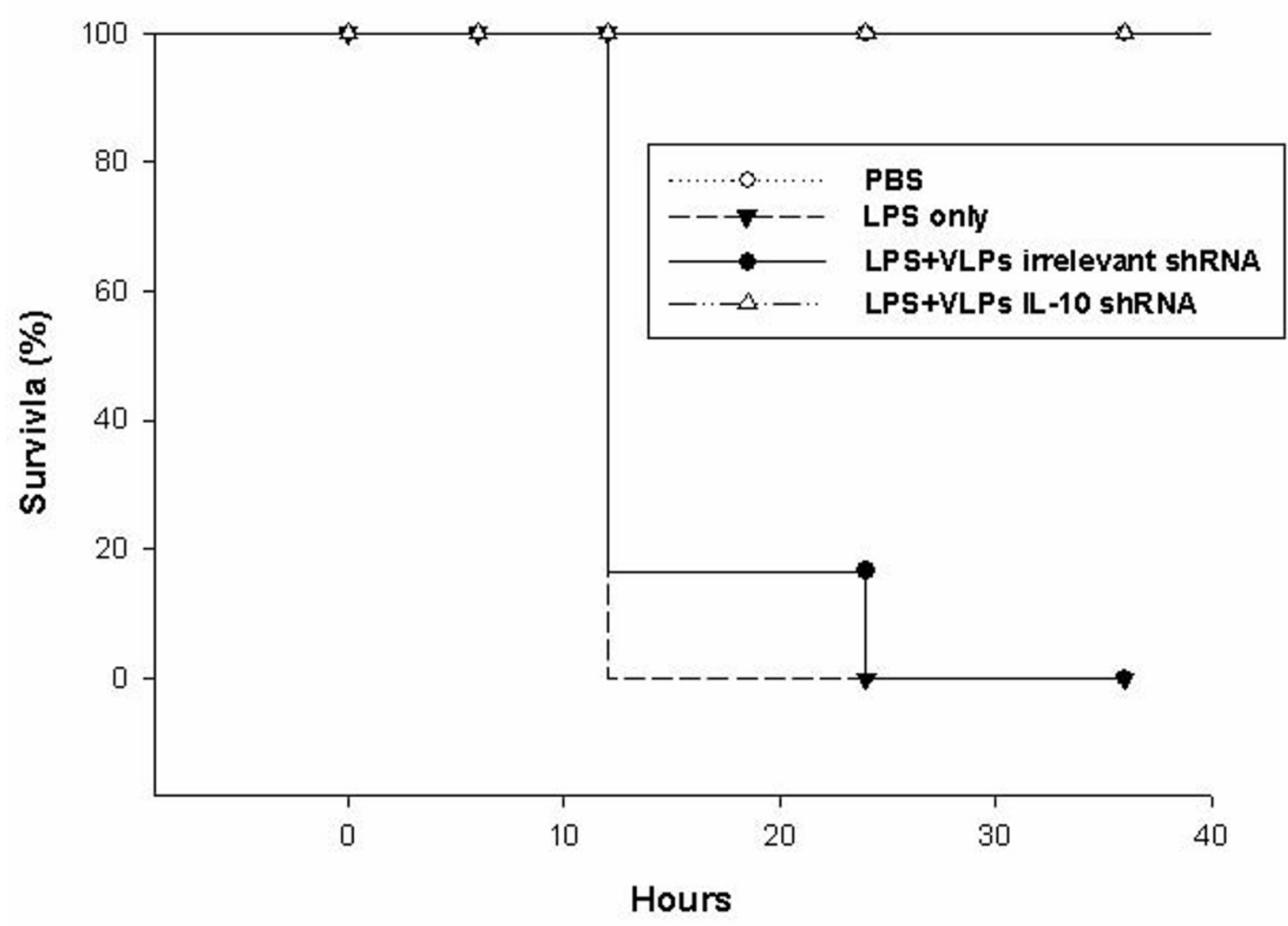

Figure 5 Outcome of BALB/c mice treated with LPS, irrelevant shRNA and IL-10 shRNA. Groups of BALB/c mice were intraperitoneally injected with LPS $(25 \mu \mathrm{g})$. After two hours, mice received intravenously VLPs-IL-10 shRNA and irrelevant shRNA. The survival rate and survival time of the animals were observed and compared between groups.

nomic, another advantage of using HU6-shRNA template is that the shRNA can be synthesized continuously as long as the DNA template exists, while siRNA will be cleaved along with target mRNA degradation.

In this study, we used two IL-10 shRNAs which target different sites of IL-10 in RAW264.7 cells and found that both IL-10 shRNAs efficiently reduced IL-10 mRNA but not TNF- $\alpha$ mRNA level (Fig 3. B). We have two reasons to believe that there is no cross reaction between IL-10 shRNA and TNF- $\alpha$ mRNA. First, both IL-10 shRNAs did not affect TNF- $\alpha$ mRNA level. Second, since RNAi is mainly functioning on mRNA level of target gene and real-time PCR is a sensitive method to quantitate the level of mRNA, we are confident that IL-10 shRNA did not react with TNF- $\alpha$ mRNA. However, down regulation of IL-10 via shRNA is accompanied by reduction of TNF- $\alpha$ level in an animal model (Fig. 4). This could be explained by the possibility that down regulation of IL-10 may affect TNF- $\alpha$ expression in other cell types through paracrine system.

Toxic shock is mediated by a complex set of cytokine interactions. Previous studies showed that infusion of LPS mimics the endotoxic state and results in the production of multiple inflammatory cytokines, including IL-1, INF- $\gamma$ and TNF- $\alpha$ production, which is known to cause tissue necrosis and organ failure. In addition to inducing the production of pro-inflammatory cytokines, LPS also triggers the release of anti-inflammatory cytokines, such as IL-10, in the bloodstream of normal mice [17]. Many cell types can produce IL-10, including phagocytic cells, conventional DCs, T cells, B cells, and NK cells. IL-10 has been implicated as a key anti-inflammatory modulator in 
the cascade of cytokine synthesis, and was identified as a critical counterbalance to proinflammatory cytokine synthesis. It acts to terminate the inflammatory response and limit inflammation-induced tissue pathology by deactivating macrophages and silencing their synthesis of TNF$\alpha$, IL-6, IL- $1 \alpha$, IL-8, and an array of other proinflammatory cytokines and chemokines. In mouse models of toxic shock, IL-10 is produced very rapidly after exposure to LPS $[18,19]$ and serum levels of INF- $\gamma$ and IL-10 peak at the same time as TNF- $\alpha$, which is known to play a central role in the pathogenesis of toxic shock. In such models, it was observed that IL-10 appears in the serum within one hour after LPS challenge and persists in the blood for at least six hours $[18,19]$. Subsequently, it was found that a single injection of IL-10 prevented death in murine models of LPS-induced toxic shock, and maximum protection was afforded only when IL-10 was given shortly before or after IL-10 challenge $[18,20]$. Neutralization of endogenously produced IL-10 by administration of anti-IL-10 monoclonal antibody $2 \mathrm{~h}$ before LPS challenge resulted in a marked increase in both TNF- $\alpha$ and IFN- $\gamma$ serum levels, and high mortality rates [19], suggesting that the rapid release of IL-10 during endotoxemia is a natural antiinflammatory response controlling cytokine production and LPS toxicity. Increased lethality was also observed when anti-IL-10 antibody treatment was given at the same time as LPS [19,21], but not when the antibody treatment was delayed until 3 hours after challenge [21], suggesting that IL-10 mediates protection in the earliest phase of the LPS response. In the current study, the antiIL-10 shRNA was administered to mice two hours after LPS injection. This could explain, only in part, the beneficial effects on survival we have observed.

Another potential explanation stems from the complexity of functions played by IL-10 in the immune system. Although IL-10 is considered a potent antiinflammatory cytokine, studies have suggested that IL-10 also possesses immunostimulatory effects [22,23]. When administered 1 $\mathrm{h}$ after LPS injection, it potentiated LPS-induced IFNrelease, which was associated with elevated levels of the IFN-dependent chemokines. In addition, IL-10 treatment enhanced activation of CTL and NK cells after LPS injection. Since, under certain conditions, IL-10 has proinflammatory functions in vivo, stimulating CD4+, CD8+ T cells, and/or NK cells, it is possible that the anti-IL-10 shRNA used in the current work blocked profoundly IL10 production in several cell types, leading to less inflammation and lower mortality rates in mice exposed to toxic shock.

In this study, BALB/c mice treated with IL-10-VLPsshRNA decreased production of IL-10 (93\% suppression). This finding provides a good model using JCV VLPs as a delivery tool for RNAi in vivo. IL-10 is a key regulator of the immune system and has been reported to be associ- ated the development of SLE. The decrease in the expression level of IL-10 may contribute to the amelioration of the disease symptoms in human SLE [9]. It has been reported that treatment with anti-IL-10 antibody delayed onset of autoimmunity in (NZW/NZB)F1 mice and led to a reduction in disease activity $[10,11]$. RNAi offers the prospects of higher specificity, lower immunogenicity, and greater disease modification than current antibody therapies.

In conclusion, JCV VLPs is an easily prepared agent capable of effectively delivering RNAi in vitro and in vivo without significant cytotoxicity. The system provides an efficient tool for delivering the RNAi for the possibility of gene therapy in the future.

Competing interests

The authors declare that they have no competing interests.

\section{Authors' contributions}

MIC and YFH contributed equally to this work. MIC and YFH interpreted the data and drafted the manuscript. MIC, MW, DC and JTC designed and performed the RNAi and JC virus experiments. MZ and GJT conceived of this study, and participated in its design and coordination. All authors read and approved the final manuscript.

\section{Acknowledgements}

This work was supported by a collaborative grant from Inserm (Paris, France) and NSC (Taipei, Taiwan) (NSC 95-2314-B-040-027)

\section{Author Details}

IInstitute of Medicine, Chung Shan Medical University, Taichung, Taiwan, IInstitue of Immunology, Chung Shan Medical University, Taichung, Taiwan, 3Department of Microbiology and Immunology, Chung Shan Medical University, Taichung, Taiwan, ${ }^{4}$ Institute of Medical and Molecular Toxicology, Chung Shan Medical University, Taichung, 40201, Taiwan, ${ }^{5}$ Department of Life Science, National Chung Cheng University, Chiayi County, Taiwan, 6 Institute National de la Santé et de la Recherche Médicale, INSERM U606, Centre Viggo Petersen, Hôpital Lariboisière, 2, Paris CEDEX 10, France, 7 University Denis Diderot Paris 7, 75475 Paris, France and ${ }^{8}$ Department of Internal Medicine, Chung Shan Medical University Hospital, Taichung, Taiwan

Received: 7 April 2010 Accepted: 24 June 2010

Published: 24 June 2010

\section{References}

1. Soutschek J, Akinc A, Bramlage B, Charisse K, Constien R, Donoghue M, Elbashir S, Geick A, Hadwiger P, Harborth J, John M, Kesavan V, Lavine G, Pandey RK, Racie T, Rajeev KG, Rohl I, Toudjarska I, Wang G, Wuschko S, Bumcrot D, Koteliansky V, Limmer S, Manoharan M, Vornlocher HP: Therapeutic silencing of an endogenous gene by systemic administration of modified siRNAs. Nature 2004, 432(7014):173-178

2. Shankar $P$, Manjunath N, Lieberman J: The prospect of silencing disease using RNA interference. Jama 2005, 293(11):1367-1373.

3. Howard KA: Delivery of RNA interference therapeutics using polycation-based nanoparticles. Adv Drug Deliv Rev 2009, 61:710-720.

4. Chang D, Fung CY, Ou WC, Chao PC, Li SY, Wang M, Huang YL, Tzeng TY, Tsai RT: Self-assembly of the JC virus major capsid protein, VP1, expressed in insect cells. J Gen Virol 1997, 78(Pt 6):1435-1439.

5. Wang M, Tsou TH, Chen LS, Ou WC, Chen PL, Chang CF, Fung CY, Chang D: Inhibition of simian virus 40 large tumor antigen expression in human fetal glial cells by an antisense oligodeoxynucleotide delivered by the JC virus-like particle. Hum Gene Ther 2004, 15(11):1077-1090.

6. Goldmann C, Stolte N, Nisslein T, Hunsmann G, Luke W, Petry H: Packaging of small molecules into VP1-virus-like particles of the human polyomavirus JC virus. J Virol Methods 2000, 90(1):85-90.

7. Hagiwara E, Gourley MF, Lee S, Klinman DK: Disease severity in patients with systemic lupus erythematosus correlates with an increased ratio 
of interleukin-10: interferon-gamma-secreting cells in the peripheral blood. Arthritis Rheum 1996, 39(3):379-385.

8. Llorente L, Richaud-Patin Y, Fior R, Alcocer-Varela J, Wijdenes J, Fourrier BM, Galanaud P, Emilie D: In vivo production of interleukin-10 by non-T cells in rheumatoid arthritis, Sjogren's syndrome, and systemic lupus erythematosus. A potential mechanism of B lymphocyte hyperactivity and autoimmunity. Arthritis Rheum 1994, 37(11):1647-1655.

9. Llorente L, Richaud-Patin Y, Garcia-Padilla C, Claret E, Jakez-Ocampo J, Cardiel MH, Alcocer-Varela J, Grangeot-Keros L, Alarcon-Segovia D, Wijdenes J, Galanaud P, Emilie D: Clinical and biologic effects of antiinterleukin-10 monoclonal antibody administration in systemic lupus erythematosus. Arthritis Rheum 2000, 43(8):1790-1800.

10. Yin Z, Bahtiyar G, Zhang N, Liu L, Zhu P, Robert ME, McNiff J, Madaio MP, Craft J: IL-10 regulates murine lupus. J Immuno/ 2002, 169(4):2148-2155.

11. Ishida H, Muchamuel T, Sakaguchi S, Andrade S, Menon S, Howard M: Continuous administration of anti-interleukin 10 antibodies delays onset of autoimmunity in NZB/W F1 mice. J Exp Med 1994, 179(1):305-310

12. Chen PL, Wang M, Ou WC, Lii CK, Chen LS, Chang D: Disulfide bonds stabilize JC virus capsid-like structure by protecting calcium ions from chelation. FEBS Lett 2001, 500(3):109-113.

13. Chang JT: An economic and efficient method of RNAi vector constructions. Anal Biochem 2004, 334(1):199-200.

14. Ou WC, Wang M, Fung CY, Tsai RT, Chao PC, Hseu TH, Chang D: The major capsid protein, VP1, of human JC virus expressed in Escherichia coli is able to self-assemble into a capsid-like particle and deliver exogenous DNA into human kidney cells. J Gen Virol 1999, 80(Pt 1):39-46.

15. Chen LS, Wang M, Ou WC, Fung CY, Chen PL, Chang CF, Huang WS, Wang $J Y$, Lin PY, Chang D: Efficient gene transfer using the human JC virus-like particle that inhibits human colon adenocarcinoma growth in a nude mouse model. Gene Ther. DOl: gt. 2010.50

16. Suzuki S, Sawa H, Komagome R, Orba Y, Yamada M, Okada Y, Ishida Y, Nishihara H, Tanaka S, Nagashima K: Broad distribution of the JC virus receptor contrasts with a marked cellular restriction of virus replication. Virology 2001, 286(1):100-112.

17. Moore KW, O'Garra A, de Waal Malefyt R, Vieira P, Mosmann TR: Interleukin-10. Annu Rev Immunol 1993, 11:165-190.

18. Durez P, Abramowicz D, Gerard C, Van Mechelen M, Amraoui Z, Dubois C, Leo O, Velu T, Goldman M: In vivo induction of interleukin 10 by antiCD3 monoclonal antibody or bacterial lipopolysaccharide: differential modulation by cyclosporin A. J Exp Med 1993, 177(2):551-555.

19. Marchant A, Bruyns C, Vandenabeele P, Ducarme M, Gerard C, Delvaux A, De Groote D, Abramowicz D, Velu T, Goldman M: Interleukin-10 controls interferon-gamma and tumor necrosis factor production during experimental endotoxemia. Eur J Immunol 1994, 24(5):1167-1171.

20. Howard M, Muchamuel T, Andrade S, Menon S: Interleukin 10 protects mice from lethal endotoxemia. J Exp Med 1993, 177(4):1205-1208.

21. Berg DJ, Kuhn R, Rajewsky K, Muller W, Menon S, Davidson N, Grunig G, Rennick D: Interleukin-10 is a central regulator of the response to LPS in murine models of endotoxic shock and the Shwartzman reaction but not endotoxin tolerance. J Clin Invest 1995, 96(5):2339-2347.

22. Lauw FN, Pajkrt D, Hack CE, Kurimoto M, van Deventer SJ, van der Poll T: Proinflammatory effects of IL-10 during human endotoxemia. J Immunol 2000, 165(5):2783-2789.

23. Kaneko T, Itoh M, Nakamura Y, limura A, Hayashi S, Takahashi K, Stivala F, Bendtzen K, Nicoletti F: Proinflammatory effects of exogenously administered IL-10 in experimental autoimmune orchitis. Cytokine 2003, 22(1-2):50-53.

doi: $10.1186 / 1423-0127-17-51$

Cite this article as: Chou et al., In vitro and in vivo targeted delivery of IL-10 interfering RNA by JC virus-like particles Journal of Biomedical Science 2010, 17:51

\section{Submit your next manuscript to BioMed Central} and take full advantage of:

- Convenient online submission

- Thorough peer review

- No space constraints or color figure charges

- Immediate publication on acceptance

- Inclusion in PubMed, CAS, Scopus and Google Scholar

- Research which is freely available for redistribution

Submit your manuscript at www.biomedcentral.com/submit
C Biomed Central 